\title{
Are crop and range lands being contaminated with cadmium and lead in sediments transported by wind from an adjacent contaminated shallow lake?
}

\author{
H. O. Rubio ${ }^{1}$, T. R. Saucedo ${ }^{1}$, M. R. Bautista ${ }^{2}$, K. Wood $^{3}$, \\ C. Holguin ${ }^{3} \&$ J. Jiménez ${ }^{4}$ \\ ${ }^{I}$ Campo Experimental la Campana-Madera del Instituto Nacional de \\ Investigaciones Forestales, Agrícolas y Pecuarias, México y Facultad de \\ Zootecnia de la Universidad Autónoma de Chihuahua, México \\ ${ }^{2}$ Universidad Juárez Autónoma de Tabasco \\ ${ }^{3}$ New Mexico Water Resources Research Institute, Las Cruces, \\ New Mexico, USA \\ ${ }^{4}$ Facultad de Zootecnia de la Universidad Autónoma de Chihuahua, \\ México
}

\begin{abstract}
Soil contamination by cadmium $(\mathrm{Cd})$ and lead $(\mathrm{Pb})$ in range and crop lands can occur from polluted sediments carried by the wind. Soils samples were obtained in three different areas on the leeward (east) side of a shallow lake called the Laguna de Bustillos: (1) sediment in the shallow lake (S), (2) soil in the range area adjacent to the shallow lake (RA), and (3) soil in agriculture land (AL) adjacent to the range area. In each area, three composite soil samples were randomly collected at depths of $0-15,15-30$ and $30-50 \mathrm{~cm}$. Therefore, 45 soil samples were analyzed as a 3 (area) x 3 (depth) factorial arrangement. The samples were air dried, passed through a $2.0 \mathrm{~mm}$ sieve, ground and passed through a $0.355 \mathrm{~mm}$ sieve, and digested with concentrated nitric acid. The metals $\mathrm{Cd}$ and $\mathrm{Pb}$ were determined using ICP optical emission spectrometry. In addition $\mathrm{pH}$ and $\mathrm{CE}$ were evaluated. Cadmium concentration was statistically different among areas and showed a strong interaction between depth $\mathrm{x}$ area. Maximum $\mathrm{Cd}$ concentration was found in $\mathrm{S}$ with $0.94 \mathrm{mg} \mathrm{kg}^{-1}$ in the surface horizon (0-15 $\mathrm{cm})$. Lead concentration was different among areas and the interaction was not as strong as the one noted for $\mathrm{Cd}$. Highest $\mathrm{Pb}$ concentrations were observed in the surface horizons $(0-15 \mathrm{~cm})$ of both $\mathrm{S}$ and RA with $74.19 \mathrm{mg} \mathrm{kg}^{-1}$ and 55.09 $\mathrm{mg} \mathrm{kg}^{-1}$. Nevertheless, for the AL system the maximum $\mathrm{Pb}$ concentration was found in the subsurface horizon $(30-50 \mathrm{~cm})$ with $40.23 \mathrm{mg} \mathrm{kg}^{-1}$. It is concluded that $\mathrm{Cd}$ and $\mathrm{Pb}$ are contaminating the RA and $\mathrm{AL}$ through wind movement with $\mathrm{Pb}$ contamination being the worst.
\end{abstract}

Keywords: cadmium, lead, soil contamination, laguna Bustillos, Chihuahua, México. 


\section{Introduction}

Cadmium $(\mathrm{Cd})$ and lead $(\mathrm{Pb})$ are considered to be at the top of the five most important elements in terms of food-chain contamination. These two metals, when present in highly contaminated soils may have a negative human reproductive outcome [1]. It is generally recognized that the presence of these metals in soils is usually thorough antrophogenic activities such as agriculture (fertilizers, liming materials, agrochemicals), industry (atmospheric deposition, wastes) and urban activities (sewage sludges, drainage deposition) whereas other elements in soils are often derived from the parent rock material which the pedogenetic processes are carried out. Once in soil, the metals as contaminants, often attach to soil particles that can migrate from one place to another.

Evaluation of heavy metals contamination is often based on comparison with the background concentration in a given environment [2], evaluating the effect on plant growth or soil utilization $[3,4]$ and determining the hazard to human health $[5,6]$. It is generally accepted that soil sediment is a more complex medium than water. This is true because soils include water as well as solid and gas phases, and soils do not move from one place to another as fast as does water [7], and determining concentrations of heavy metals is a difficult task [8].

The water of the Laguna de Bustillos in Chihuahua, México is highly contaminated [9, 10] and it is suspected that its soil sediments are also contaminated. In the particular case of the Laguna de Bustillos environment, the sediment is exposed because the water of the shallow lake is absent during large periods of time. For example, during the year 2005 (January to July) most of the shallow lake was completely dry. In addition, strong wind events are present in the period from February to April every year. Therefore, the question that arises is whether the soil sediment from the shallow lake is contaminating the close rangeland and agriculture land. The objective was to evaluate the level of soil contamination with $\mathrm{Cd}$ and $\mathrm{Pb}$ metals in three different environments; lake sediments, rangeland, and agriculture land. To our knowledge, this is the first report on contaminant risk assessment of rangeland and cropland soils from a polluted soil in Mexico.

\section{Materials and methods}

The study was conducted on the east side of the Laguna de Bustillos, located in the state of Chihuahua, México. Its location is in the polygon: latitude $28^{\circ} 58^{\prime}$ $12^{\prime \prime}-28^{\circ} 15^{\prime} 00^{\prime \prime} \mathrm{N}$; longitude $107^{\circ} 09^{\prime} 36^{\prime \prime}-106^{\circ} 15^{\prime} 00^{\prime \prime} \mathrm{W}$ and at 2,300 meters elevation (Figure 1). Annual precipitation averages about $480 \mathrm{~mm}$ mostly as rain during the summer (July to September), but some snow events occur during the winter (December to February). The source is a shallow lake, heavily silted due to soil erosion coming from a denuded watershed which becomes dry during drought periods. Wind storms moving from the west to the east side usually occur every year from late winter (February) through the beginning of spring (April). 


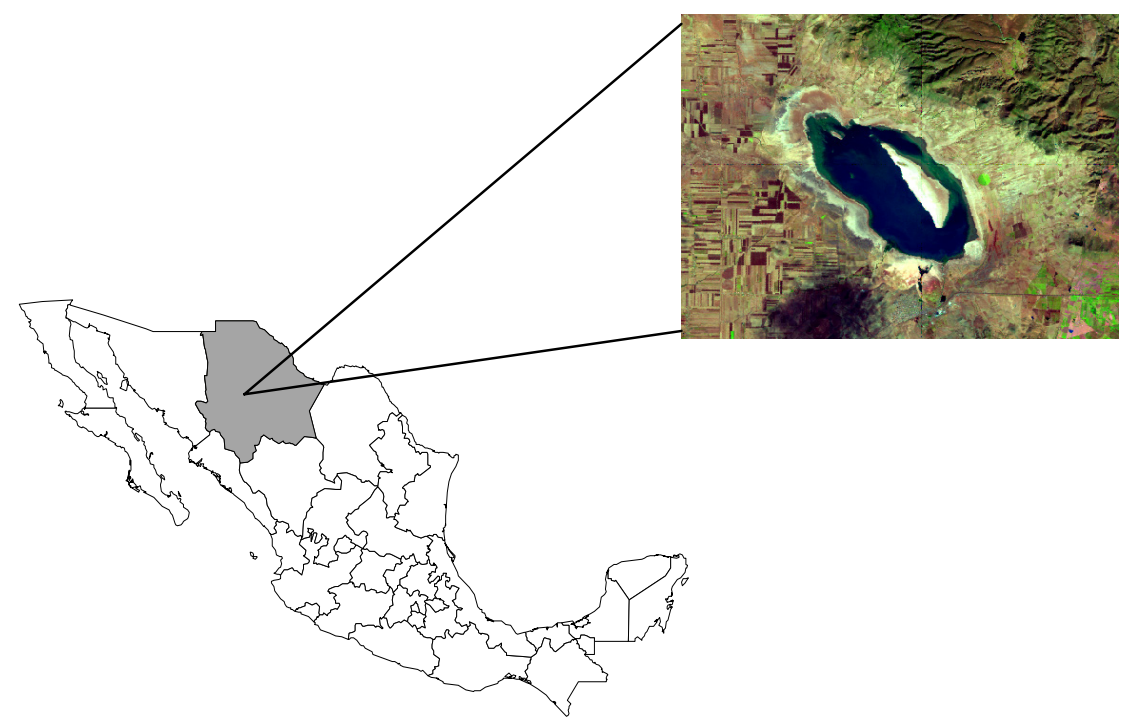

Figure 1: A panoramic view of the Laguna de Bustillos, Chihuahua, Mexico.

Soil samples where obtained from three different areas on the leeward (east) side of the Laguna de Bustillos. The first system was the sediment of the shallow lake (S) where the water used to be, but at the time of collecting the sample was dry. The second area was the rangeland (RL) adjacent to the shallow lake where the domestic livestock graze during the whole year. The third area was the crop land (AL) that is close to the RL. The domestic livestock belong to the commonly owned communities (Ejidos) of Cuitlahuac, La Selva, Centro Calles and Fabela. An "Ejido" is a community where the law established that any grazing land must be collectively shared [11] which results in the worldwide phenomena commonly called "The Tragedy of the Commons"; therefore, the RL is an extremely deteriorated grassland. The most important crops in the AL are beans (Phaseoluos vulgaris), corn (Zea mays) and oats (Avena sativa) growing in the precipitation season under dryland condition.

Five points were randomly selected in the shallow lake (S). Then, at each point of $\mathrm{S}$ a transectal line to the east was selected with five randomly located points in RL as well as in AL. At each point, three composite soil samples were taken at $0-15,15-30$, and $30-50 \mathrm{~cm}$ profile depths. Hence, 15 soil samples were taken in each system, giving a total of 45 soil samples. The samples were air dried and passed through a $2.0 \mathrm{~mm}$ sieve. After this, the samples were ground and passed through a $0.355 \mathrm{~mm}$ sieve. They were evaluated for $\mathrm{Cd}$ and $\mathrm{Pb}$ concentration as well as $\mathrm{pH}$ and EC. The digestion of soil samples for $\mathrm{Cd}$ and $\mathrm{Pb}$ evaluation was realized with concentrated nitric acid in the laboratory of the Faculty of Zootechnic of the Autonomus University of Chihuahua, Mexico, following the sampling and analysis protocol of Canada (MAF). $\mathrm{Cd}$ and $\mathrm{Pb}$ 
concentrations were determined using an ICP-OES (Inductively Coupled Plasma-Optical Emission Spectrometry) 2100, Perkin Elmer. Values of pH and EC were determined in a saturated paste using a standard glass electrode and a conductivity meter, respectively. The statistical analysis used a factorial treatment design $3 \times 3$; where Factor A was the system (S, RL, AL) and Factor B was the depth $(0-15,15-30,30-50 \mathrm{~cm})$. The differences were noted using a 0.01 significance level.

\section{Results and discussion}

The Cd concentration was different among systems. Not surprisingly the higher $\mathrm{Cd}$ concentration was noted in $\mathrm{S}$, with the high concentration noted in the upper horizon (0-15) where it was detected at $0.946 \mathrm{mg} \mathrm{kg}^{-1}$ in comparison with 0.672 $\mathrm{mg} \mathrm{kg}^{-1}$ found at the $15-30 \mathrm{~cm}$ depth and $0.614 \mathrm{mg} \mathrm{kg}^{-1}$ noted in the $30-50 \mathrm{~cm}$ depth. In contrast, in $\mathrm{RL}$ and $\mathrm{Al}$, the higher $\mathrm{Cd}$ concentration was not detected in the upper profile $(0-15 \mathrm{~cm})$; in fact, the lowest concentration in these two areas was found in the upper horizon (Figure 2). A strong interaction was noted in $\mathrm{Cd}$ concentrations (Figure 2). These results are similar to the levels found in $\mathrm{Cd}$ concentrations in a soil of West Bengal, India where it was detected at $0.37 \mathrm{mg}$ $\mathrm{kg}^{-1}$ [12], soil samples form England and Wales had a Cd concentration of 0.8 $\mathrm{mg} \mathrm{kg}^{-1}$ [13] and China soils had a Cd concentration of $0.07 \mathrm{mg} \mathrm{kg}^{-1}$ [14]. In other studies, Cd levels were $0.4-0.8 \mathrm{mg} \mathrm{kg}^{-1}$ in Spain [15], levels of 0.6-1.4 mg $\mathrm{kg}^{-1}$ in asphalt roads in Germany [16] and levels of $0.41 \mathrm{mg} \mathrm{kg}^{-1}$ in Japan [17].

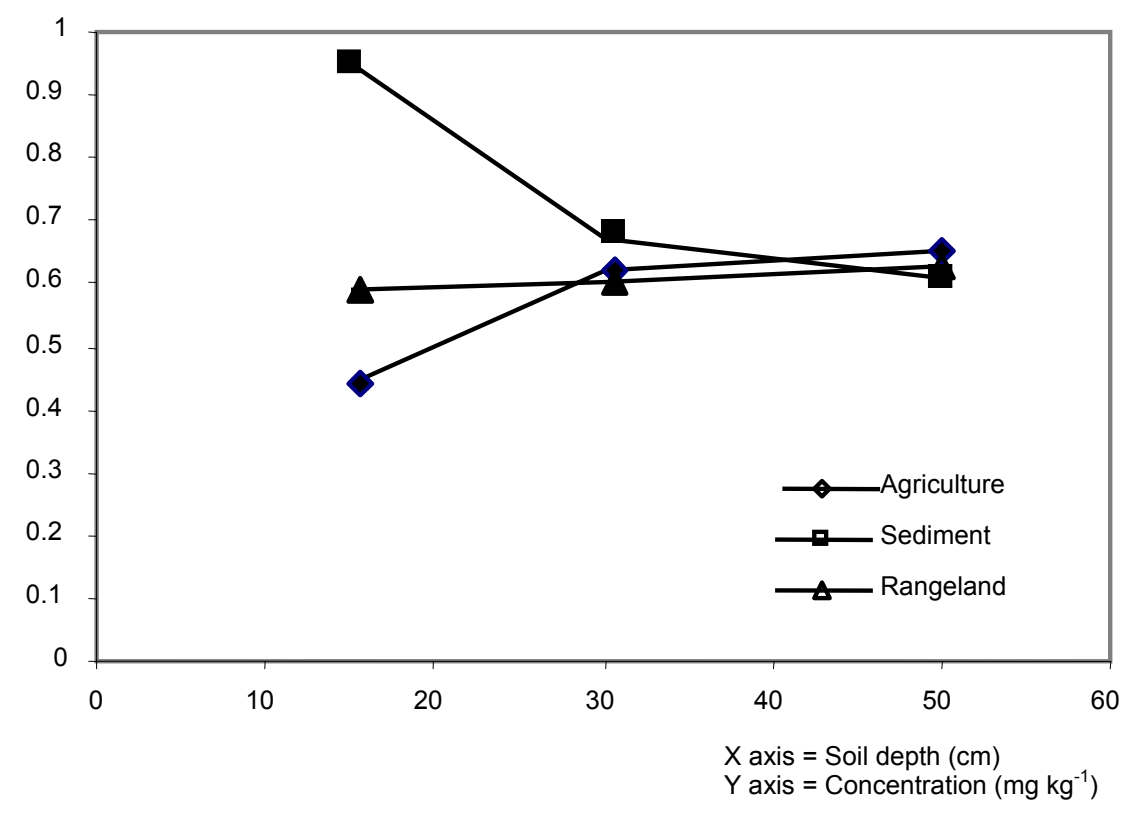

Figure 2: Mean of Cadmium level under three systems and different soil depth. 
A study in the United States of America [18] found 3,045 surface soil samples contained $\mathrm{Cd}$ values from $<0.01$ to $2.0 \mathrm{mg} \mathrm{kg}^{-1}$ with a mean of $0.265 \mathrm{mg} \mathrm{kg}^{-1}$. In any case, the levels of $\mathrm{Cd}$ found in the present study do not represent a hazard to the soils in the three areas, because Dudka et al. [18] concluded that soils with $\mathrm{Cd}$ concentrations of up to $30 \mathrm{mg} / \mathrm{kg}$ are still safe for production of some crop plants. Moreover, the soil contamination due to wind-born $\mathrm{Cd}$ was insignificant, being our hypothesis not tested for this element.

The $\mathrm{Pb}$ concentrations were different among areas and no statistical differences were observed for depth and for the interaction (Figure 3). Maximum levels of $\mathrm{Pb}$ concentration was noted in $\mathrm{S}$ with the higher concentration in the profile 15-30 cm depth with about $75.99 \mathrm{mg} \mathrm{kg}^{-1}$ while the lesser amount of $\mathrm{Pb}$ was observed in AL system in the upper profile with $33.49 \mathrm{mg} \mathrm{kg}^{-1}$ (Figure 3). A study evaluating surface soils in a greenhouse [15] found $\mathrm{Pb}$ concentrations in a range of 2.5 to $89.9 \mathrm{mg} \mathrm{kg}^{-1}$ which are similar to the results presented in this study; but the concentration range was shorter from 33.49 to $75.99 \mathrm{mg} \mathrm{kg}^{-1}$. Another study [19] reported a Pb concentration as high as $59 \mathrm{mg} \mathrm{kg}^{-1}$ in the $0-20$ $\mathrm{cm}$ depth of the soil profile irrigated with wastewater. Moreover, in a study carried out in India [12] they reported a mean concentration of $10.4 \mathrm{mg} \mathrm{kg}^{-1}$ in a soil affected with arsenic. A study carried out in Japan [17] noted a $21 \mathrm{mg} \mathrm{kg}^{-1}$ of $\mathrm{Pb}$ in an uncultivated soil. The values reported here are of practical importance, because some of the soil fauna like the earthworm (Eisenia fetida Andrei) may be severely affected with $\mathrm{Pb}$ concentration higher than $30 \mathrm{mg} \mathrm{kg}^{-1}$.

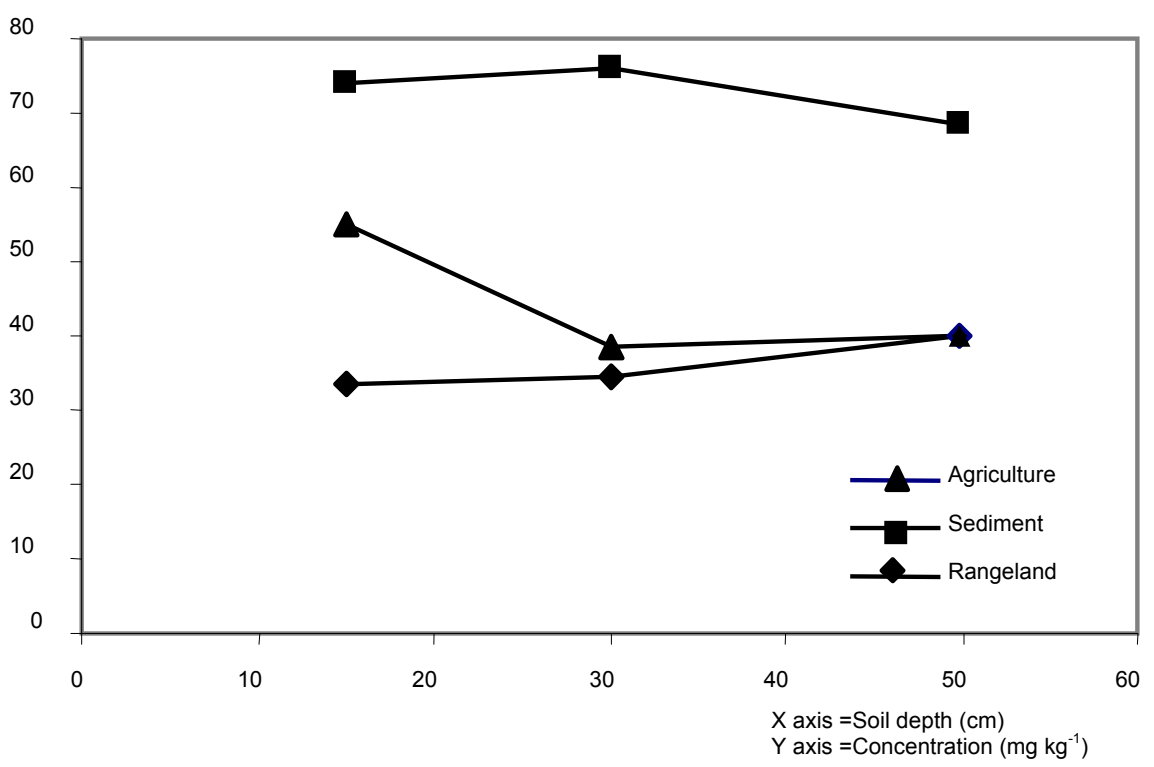

Figure 3: Mean of lead concentration under three different systems and different soil depth. 
A study conducted on road dust in Sydney [20] suggested that deposition and removal of road dust is not a static process. We could speculate that our findings suggest that $\mathrm{Cd}$ and $\mathrm{Pb}$ had similar origin and this is a continuous process. This means that an equilibrium may be reached when the rate of deposition in a system is equal to the rate of removal.

\section{Conclusion}

This study showed that our hypothesis that sediments of the Laguna de Bustillos are contaminating the rangelands and crop lands with $\mathrm{Cd}$ and $\mathrm{Pb}$ is true. However, the $\mathrm{Cd}$ concentration does not represent a hazard at least in the area tested. On the other hand, the $\mathrm{Pb}$ concentration in the contaminated area may represent a potential hazard in the short term.

\section{Acknowledgements}

We are deeply grateful with the Produce Foundation of Chihuahua (Fundacion Produce Chihuahua, A.C.) for partial financial support as well as with the Faculty of Zootechnic of the Autonomous University of Chihuahua. The INIFAP (National Research Institute of Forestry, Agriculture and Rangeland) deserves special thanks for financial support and for facilities given to this research.

\section{References}

[1] Laudanski, T., Sipowicz, M., Modszelewski, P., Bolinski, J., Szamatowicz, J., Razniewska, G., and Akerlund, M. 1991. Influence of high lead and cadmium soil content on human reproductive outcome. Int. J. Gynaecol. Ostet. 36(4):309-315.

[2] Zhang, X.P., Deng, W., and Yang, X.M. 2002. The background concentrations of 13 soil trace elements and their relationship to parent material and vegetation in Xizang (Tibet), China. J. Asian Earth Sci. 21:167-174.

[3] Arao, T de N., Sugiyama, M., and Takahashi, M., 2003. Genotypic differences in cadmium uptake and distribution in soybeans. Plant Soil 251:247-253.

[4] Sheppard, S.C. 2005. Assessment of long-term fate of metals in soils: Inferences from analogues. A review. Canadian Jour. of Soil Sci. 85(1):118

[5] Storelli, M.M., Barone, G., and Marcotrigiano, G.O. 2005. Cadmium in cephalopod molluscs: implications for public health. Journal of Food Protection 68(3):577-588.

[6] Linde, A.R., Sanchez-Galan, S., and García-Vazquez, E. 2004. Heavy metal contamination of European Eel (Anguilla anguilla) and brown trout (Salmo trutta) caught in wild ecosystems in Spain. Journal of Food protection 67(10): 2332-2336. 
[7] Peijnenburg, W.J.G.M. and Jager, T. 2003. Monitoring approaches to access bioaccessibility and bioavailability of metals: matrix issues. Ecotoxicol. Environ. Saf. 56:63-77.

[8] Chen, M., Ma, L.Q. and Harris, W.G. 1999. Baseline concentrations of 15 trace elements in Florida surface soils. J. Environ. Qual. 28:1173-1181.

[9] CNA, 2003. Comision Nacional del Agua. Estadísticas del agua en México. Reporte.

[10] Rubio, A.H., Saucedo, R.A., Lara, C.R., Wood, K., and Jimenez, J. 2005. Water quality in the Laguna de Bustillos of Chihuahua, México. Water Resources Management III. Editors M. De Conceicao Cunha and C.A. Brebbia. 155-160.

[11] Cornehls, J.V. 1964. Mexico's rural road to progress: an analysis of agrarian reform and agricultural development. Univ. of Texas, Austin, USA.

[12] Roychowdhury, T., Uchino, T., Tokunaka, H., abd Ando, M. 2002. Arsenic and other heavy metals in soils from an arsenic-affected area of West Bengal, India. Chemosphere 49(6)605-618.

[13] McGrath, S.P. and Loveland, P.J. 1992. Heavy metals in soils. In the soil geochemical atlas of England. B.J. Alloway (ed.). Blackie Academic and Professional, Glasgow, Scotland.

[14] Wang, Y., and Wei, F.S. (eds.), 1995. Soil environmental element chemistry. Chinese Environmental Science Press, Peking, People's Republic of China.

[15] Gil, C., Boluda, R., and Ramos, J. 2004. Determination and evaluation of cadmium, lead and nickel in greenhouse soils of Almeria (Spain). Chemosphere 55(7)1027-1034.

[16] Munch, D. 1992. Soil contamination beneath asphalt roads by polynuclear aromatic hydrocarbons zinc, lead and cadmium. Science of the Total Environments 126(1-2):49-60.

[17] Akira, T., Hirofumi, T., Masami, N., Yuichi, T., Toyokazu, U., Shun'ichi, H., Jiro, I. 2005. Effect of long-term fertilizer application on the concentration and solubility of major and trace elements in a cultivated andisol. Soil Sci. Plant Nutr. 51(2)251-260.

[18] Dudka, S., Piotrowska, M., and Terelak, H. 1996. Transfer of cadmium, lead, and zinc from industrially contaminated soil to crop plants: a field study. Empoissonnement Pollution 94(2)181-188

[19] Mapanda, F., Mangwayana, E.N., Nyamangara, J., and Giller, K.E. 2005. The effect of long-term irrigation using wastewater on heavy metal contents of soils under vegetables in Harare, Zimbabwe. Agriculture, Ecosystem\&Environment 107(2-3)151-165

[20] Ball, J.E., Jenks, R., Aubourg, D. 1996. Dry weather build-up of constituents on road surfaces. In proceedings of the $7^{\text {th }}$ International Conference on Urban Storm Drainage. Hanover, Germany 785-790. 